\title{
logistic Distribution
}

4 Mark W. Milke*, Vincent Wong ${ }^{1}$, Department of Civil Engineering, University of

5 Canterbury, Private Bag 4800, Christchurch, 8140, New Zealand.

6 Edward A. McBean, School of Engineering, University of Guelph, Guelph, Ontario,

7 Canada.

8

\section{Abstract}

10 Variations in solid waste composition data are necessary as inputs to solid waste

11 planning, yet uncertainty exists regarding which probability distributions might be

12 generally valuable to describe the variability. Twenty-two detailed analyses of solid

13 waste from British Columbia, Canada, are fit to distributions using the BestFit

14 software. Alternative distributions are ranked based on three goodness-of-fit parameters and twelve waste fractions. The log-logistic distribution is found to be the most able to fit over the wide range of composition types considered. The results are demonstrated to be insensitive to the number of waste components or to the choice of a two- or three-parameter distribution. Although other distributions are able to match better the waste composition for individual waste types, the log-logistic distribution is demonstrated to fit, overall, a wide variety of waste composition types.

Keywords: log-logistic distribution; solid wastes, composition data analysis; goodness-of-fit; BestFit.

\footnotetext{
${ }^{*}$ Contact Author: mark.milke@canterbury.ac.nz, ph 64-03-3642-248, fax 64-03-3642-758

${ }^{1}$ Currently at Christchurch City Council.
} 


\section{Introduction}

26 Short-term (daily or truck-to-truck) variations in the composition of municipal solid 27 waste can be important in a variety of planning and management situations. The 28 variation can influence the choice of design capacity (for example, to store a recycled 29 fraction at a materials recovery facility), or the risk of regulatory violation (for example, from a hazardous material introduced to an incinerator), or can direct

31 advertising (to improve recycling efforts for specific areas). An understanding of the amount and type of variation is also needed to analyse a data set (for example, to set confidence bounds or to identify erroneous data points).

35 Two types of variations in solid waste composition are commonly seen in a histogram 36 of data. First, many composition data sets are symmetrical about the mean, and the normal distribution is commonly used to describe data. However, this distribution requires a standard deviation smaller than the mean; in other words, the coefficient of variation $(\mathrm{C} . \mathrm{V}$.$) , which is the ratio of the standard deviation to the mean, has to be$

40 less than unity. The other type of variation is seen with data where the histogram has 41 a long right-hand tail (also called positive skewness) and a relatively low mean. This distribution type can have a C.V. near or greater than unity. Many distributions can

43 be used to describe data of this type, including the lognormal, extreme value, logistic, 44 log-logistic, inverse Gauss, and Pearson distributions. Many of these distributions 45 have multiple variations, the most common feature being a parameter that shifts the distribution without changing its shape. 
Analysts can choose to pick a different probability distribution each time they need to describe variability in composition; however, this has disadvantages when attempting comparisons of variability between different solid waste components or over time.

51 The use of multiple distribution types requires transformations between parameters,

52 and the differing shapes of the distributions make it difficult to identify trends in

53 variations even after transformations are made. Use of a single transformation for 54 describing most of the common variations would make it easier for analysts to understand and explain the variability of data and their implications.

This research points to the potential broad use of the log-logistic function for describing variability in solid waste composition data. The log-logistic distribution has found use in a variety of disciplines. Ahmad et al. (1988), among others, fit river flows to the distribution for assessing floods. Gleaton and Lynch (2004) describe the strength of fibres with the distribution, while Gokhale and Khare (2005) use the distribution to describe variability in carbon monoxide concentrations at urban intersections. Calder et al. (2005) use the distribution to describe the distribution of times between rockfalls, and Kooijman (1987) uses it to describe the variability in toxicity between aquatic species.

The log-logistic distribution (Johnson, et al., 1995) can be written with a shape parameter, $\alpha$, a scale parameter, $\beta$, and a shift parameter, $\gamma$. The probability density function for the distribution is:

70

$$
f(x)=\alpha^{*}[(\mathrm{x}-\gamma) / \beta]^{\alpha-1} /\left\{\beta^{*}\left\{1+[(\mathrm{x}-\gamma) / \beta]^{\alpha}\right\}^{2}\right\}
$$


73 The cumulative distribution function, the integral of the above over $x$, is:

74

75

76

77

78

79

80

81

82

83

84

85

86

87

88

89

90

91

92

93

94 The composition data set used for this research is for waste delivered at the Burnaby

95

96

97
$\mathrm{F}(\mathrm{x})=1 /\left\{1+[\beta /(\mathrm{x}-\gamma)]^{\alpha}\right\}$
7 The mean (for $\alpha>1$ ), $m_{x}$, and standard deviation (for $\alpha>2$ ), $\sigma_{x}$, of the variable are given by:

$$
m_{x}=\left[\pi^{*} \beta^{*} \csc (\pi / \alpha) / \alpha\right]+\gamma
$$

$$
\sigma_{x}=\beta * \operatorname{sqrt}\left\{\pi *\left[2 \csc (2 \pi / \alpha)-\pi \csc ^{2}(\pi / \alpha) / \alpha\right] / \alpha\right\}
$$

4 The log-logistic function has the facility to match both types of data seen in solid waste composition. Figure 1 shows equation (1) for a high positive skew variable with a large C.V. of 1 , and for a symmetrical variable with a low C.V. of 0.1 .

This paper compares the log-logistic distribution with other distributions that could be used to fit a wide variety of solid waste composition data.

\section{Vancouver Data Set} incinerator outside of Vancouver, British Columbia, Canada, in July and October of 1998. In 1997 the incinerator received 257,460 tonnes of municipal solid waste.

These wastes were residential wastes and commercially collected wastes, of which 
121 An identical procedure was used in October of 1998 in a second study of waste 122 composition. The second study focused on a few primary waste classifications, and

much came to the incinerator from the North Shore Transfer Station. The communities from which the waste originated were suburban and moderately affluent, with blue-box kerbside collection of newsprint, metal and glass for recycling. In addition, the communities had recycling depots and beverage-bottle deposit laws.

Twenty trucks were sampled in July in proportion to the annual waste brought to the incinerator by each type of truck. Two additional trucks were sampled because of the availability of labour, giving a dataset with 22 values. For each selected truck, a portion of the contents was dumped on an asphalt surface. Then, representative parts of the portion were selected as per an ASTM method (ASTM, 1992). This was accomplished at successive representative, but random, locations throughout the dumped load. The resulting portions of waste were then placed into drums until a net sample of $136 \mathrm{~kg}$ was reached. The waste sample was first separated into eight major waste categories and placed in labelled containers and weighed. Waste in some of the eight major waste containers was further classified (e.g., paper waste was separated into office paper, newsprint, OCC, and other paper). The resulting dataset has data for 27 primary waste categories, many of which have numerous zero values and so were not analysed for this research. Some primary waste categories were further separated, giving data on a total of 36 categories. No statistically significant differences were found in the composition of wastes from the transfer station and direct haul vehicles. There were no trends over time in the data set, indicating that it is reasonable to assume independent samples. 
12320 trucks were sampled. Tables 1 and 2 summarise the data used in this paper from

124 the two sampling periods. Classifications with zero values have been excluded. The

125 dataset contains variables with a range of means and coefficients of variation, which

126 is of benefit when examining the general suitability of probability distributions to

127 solid waste composition data.

128

129

130

131

132 This research uses the software BestFit 4.5 (Palisade Corporation, 2006) to fit

133 distributions to data. The software uses a maximum likelihood estimation procedure

134 to fit the parameters to the distributions requested (Devore, 2004). Fifteen continuous

135 distributions were evaluated for goodness-of-fit (beta, exponential, extreme value,

136 gamma, inverse gauss, logistic, log-logistic, lognormal, normal, Pareto, Pearson5,

137 Pearson6, triangular, uniform, Weibull). The result of the fitting procedure is a set of

138 fitted parameters and various statistics assessing the goodness-of-fit.

139

140 There is no single, universally best way to decide goodness-of-fit of data to a

141 distribution. BestFit 4.5 provides three statistics for goodness-of-fit, all three of

142 which are used here. The three are: the Chi-square statistic, the Kolmogorov-Smirnov

143 (K-S) statistic, and the Anderson-Darling (A-D) statistic. For the Chi-square statistic,

144 the range of data is divided into a number of bins, and the number of datapoints found

145 in each bin is compared with the number of datapoints that is expected in that bin

146 based on the fitted parameters. The resulting Chi-square statistic is given by: 
150 where $\mathrm{N}_{\mathrm{i}}$ is the number of datapoints in bin $\mathrm{i}, \mathrm{E}_{\mathrm{i}}$ is the expected number of datapoints

151 in bin $\mathrm{i}$, and $\mathrm{k}$ is the number of bins. The value of the statistic depends slightly upon

152 the choice of the number of bins and their size, which is a weakness of the use of this

153 statistic for testing the goodness-of-fit for a continuous probability distribution. For

154 this work, the default bins selected by BestFit are used.

155

156 The K-S statistic is the largest difference between the cumulative distribution of the

157 data and of the fitted distribution. Because all cumulative distributions vary from 0 to

158 1, the statistic will tend to be small at the two extremes of the distribution. The

159 implication is that the K-S statistic is better at discriminating poor fit near the mean,

160 but worse at the extremes.

161

162 The A-D statistic is given by:

163

$164 A=n^{*} \int\left\{\left[F(x)-F^{\prime}(x)\right]^{2} /\left[F^{\prime}(x)^{*}\left(1-F^{\prime}(x)\right)\right]\right\} f^{\prime}(x) d x$

166 where $F(x)$ is the cumulative distribution of the actual data, $f^{\prime}(x)$ and $F^{\prime}(x)$ are the

167 probability density and cumulative probability distributions for the fitted distribution,

168 and $\mathrm{n}$ is the number of data points. In the A-D statistic, the difference between the

169 two distributions is multiplied by a weighting factor that is larger at the two tails of

170 the distribution when $\mathrm{F}(\mathrm{x})$ and $\mathrm{F}^{\prime}(\mathrm{x})$ both approach either 0 or 1 . In this way, the A-D

171 statistic is better suited to discerning which distributions fit better at the extremes. All

172 three are described in standard statistic textbooks (e.g., Johnson et al., 2004). 
177 The use of BestFit on the twelve waste components in Tables 1 and 2 resulted in a 178 number of distributions that could fit individual components. Because of the many

179 ways of defining goodness-of-fit, and because of varying goodness-of-fit

180 determinations between components, it will never be possible to say that one

181 distribution always fits the data better than others. For this study, we use a scoring

182 system to evaluate the goodness-of-fit, giving three points for the distribution

183 providing the best fit, two points for the distribution giving the second-best fit, one

184 point for the distribution giving the third-best distribution, and no points for

185 distributions giving poorer fits. With this system, a total of 216 points are assigned

186 over the twelve components and three goodness-of-fit statistics. The results in Table

1873 show the six highest-scoring distributions. The other nine distributions (e.g,

188 normal) were also tried but did not score as highly. In a few cases one of the other

189 nine distributions ranked in the top three on one of the three measures. The log-

190 logistic distribution scored the best for these two datasets.

192 Figures 2 and 3 present sample results to show how the log-logistic distribution is able 193 to fit a wide variety of data types relatively well. Figure 2 shows the paper 194 composition data, which have a relatively high mean and low coefficient of variation.

195 Both the normal and log-logistic distributions fit the data relatively well. Figure 3

196 shows the glass composition data, which have a relatively low mean and high

197 coefficient of variation. Both the lognormal and log-logistic distributions fit the data 
relatively well. However, the normal distribution does not fit the glass distribution data well, and the lognormal distribution does not fit the paper distribution data well.

\subsection{Analysis of sensitivity to coarseness of waste classification}

203 The number of waste components employed in the Burnaby incinerator dataset is 204 greater than the number found in many waste analysis studies. As a result, the means 205 are likely to be lower than those found from other datasets and hence of interest was 206 the question of the sensitivity of the results to the number of waste components 207 employed.

209 To examine this, data for specific waste components were combined into four new

210 hypothetical waste classifications. Four specific combinations were examined:

211 paper+organics, paper+plastics, metals+glass + inorganics, and metals + glass. Table 4

212 shows the best-fit distributions for these four combinations of the waste components.

213 The log-logistic distribution fits all combinations best, except for the combination of 214 paper+organics.

216 For the Burnaby dataset, the paper+organics combination has a mean of $70 \%$ of the

217 total waste stream, which is higher than all other means considered in this study. The 218 reason that the log-logistic distribution cannot fit these data well is because it is not 219 able to represent negative skew (left-hand tail). The data for this combination have a 220 slight negative skew (skewness coefficient of -0.06). The result for paper+organics 221 highlights a limitation in the use of the log-logistic function: it can be expected to fit 
solid waste composition distributions worse as the data exhibit more negative skew

223 (which is more likely as the mean increases above 50\%).

\subsection{Analysis of sensitivity to number of fitted parameters in distribution}

The distributions listed in Table 3 contain some distributions with two fitted parameters, and others, including the log-logistic, with three. One criterion for choosing a distribution is the desire to fit fewer parameters. An additional analysis parameters. The two-parameter log-logistic function (with the shift parameter, $\gamma$ in equation (1), set to 0) was fitted to the twelve waste components, and the median K-S and A-D statistics found are given in Table 5. Because the Pearson 5 distribution with three parameters also showed relatively good fit in Table 3, the two-parameter version of this distribution was also selected for analysis. The results are shown alongside that of the three-parameter log-logistic distribution.

The reduction from three parameters to two parameters would be expected to result in worse fits, and worse fits can be seen by greater K-S and A-D statistics. Table 5 shows slightly worse fit for the two-parameter log-logistic distribution compared to

241 the three-parameter form. The two-parameter Pearson 5 distribution appears to fit the 242 data worse than the two-parameter log-logistic distribution, just as was found with 243 their three-parameter forms in Table 3. The results indicate that the two-parameter 244 form of the log-logistic distribution could be a suitable generalised distribution for 245 solid waste composition data when a desire exists to reduce the number of parameters. 


\section{Discussion}

250 The common techniques used to estimate the number of samples needed to reach a

251 specified precision in solid waste composition assume a normal distribution for the 252 data (Sharma and McBean, 2006; Sfeir et al., 1999; Leroy et al., 1992). Estimates of 253 the means are commonly insensitive to the choice of the underlying distribution, 254 although this assumption could be important when estimating the standard deviation 255 or unlikely events. For example, when an unusual data point is found, it is common to 256 use techniques to estimate the likelihood of an outlier. Outlier identification 257 procedures often require the assumption of a probability distribution and so the 258 conclusion of whether the data point is erroneous or not can depend upon the assumed 259 distribution (Gilbert, 1987; McBean and Rovers, 1998). Future research into 260 techniques for analysis of solid waste composition data using the log-logistic 261 distribution would appear needed..

263 Although this analysis shows the potential for the log-logistic distribution to fit a wide 264 variety of solid waste composition data, it is important to appreciate the limitations of 265 this analysis. This study considers datasets with non-zero values. There are many 266 solid waste composition datasets where measured components have zero composition 267 in certain samples (e.g. car batteries). In these cases, it might be more appropriate to 268 use a mixed probability distribution. In addition, this study examines only one dataset 269 collected in a particular fashion, and it is possible that results will not be readily 270 transferable. 
271 The scoring system used here is relatively simplistic and the sensitivity of the results

272 to the choice of a scoring system has not been analysed. The degree to which a given

273 rank is better than another is ignored. Although similar ranking approaches are

274 commonly used in non-parametric statistics (McBean and Rovers, 1998), other

275 approaches could also be used. The data for all waste components are assumed to be

276 of equal value to a decision-maker, and the approach described herein gives them

277 each equal weight. It also ignores the distinctions seen between the measures of

278 goodness-of-fit, and so ignores the potential to give more weight to one or another.

280 Further research with additional data sets could indicate that particular distributions

281 are suited to particular waste types or data applications. This research has focused on 282 the potential for finding one distribution to fit a wide variety of waste composition 283 datasets.

285 It is easier to accept the assumption of a distribution when there is a plausible

286 mechanism that might explain why the data would tend towards a particular

287 distribution. The authors cannot provide any theoretical, underlying reason why solid 288 waste composition data should fit a log-logistic distribution. One particular weakness 289 of the log-logistic distribution is that it is not bounded at $100 \%$, and hence there will 290 always be a very small probability that over $100 \%$ of a component is found in the 291 sample, which is inappropriate. Although the Beta distribution was not able to fit the 292 data analysed here better than the log-logistic distribution, there might be other 293 bounded distributions that could provide better fits. In any case, it is important that 294 those who might use the log-logistic distribution check for the likelihood that the 
295 fitted distribution could indicate non-zero probabilities for percentages greater than $296 \quad 100 \%$.

298 The use of one probability distribution to analyse trends in multiple solid waste 299 composition data sets could have value to waste managers. These trends could exist

300 in time or in space. It is common to track specific solid waste parameters using 301 periodic sampling. The analysis of the data in one instance with one distribution, and 302 in another instance with a second will make it difficult to compare between data sets. 303 Although it could be more difficult for a waste manager to use and to explain a log304 logistic distribution than a normal or lognormal one, this research indicates that one 305 less well known distribution could provide a good fit in a wide variety of situations. 306 There are potential benefits of using a less well known distribution, and this should be 307 considered, along with ease of use, when analysing data. Further research is needed 308 into the use of one distribution to analyse trends in solid waste composition data.

\section{$311 \quad$ 5. Conclusion}

313 This research shows that although other distributions are able to match better

314 individual data, the flexibility of the log-logistic distribution makes it able to fit a 315 wide variety of solid waste composition data relatively well and, overall, better than 316 other distributions.

\section{Acknowledgements}


320 Support from the Royal Society of Edinburgh, the University of Canterbury Erskine

321 Fund, and the Canada Research Chairs program are gratefully acknowledged.

References

326 Ahmad, M.I., Sinclair, C.D., \& Werritty, A. (1998) Log-logistic flood frequency

327 analysis. Journal of Hydrology, 98, 205-224.

ASTM (1992) "Standard Test Method for the Determination of the Composition of

Unprocessed Municipal Solid Waste", D523 I-92.

332 Calder, E.S., et al. (2005) Probabilistic analysis of rockfall frequencies during an

333 andesite lava dome eruption: The Soufriere Hills Volcano, Montserrat. Geophysical

334 Research Letters, 32, n 16, L16309.

Devore, J. (2004) Probability and Statistics for Engineering and the Sciences, Sixth edition. Thomson.

Gilbert, R.O. (1987) Statistical Methods for Environmental Pollution Monitoring.

$340 \quad$ Van Nostrand Reinhold.

342 Gleaton, J.U., \& Lynch, J.D. (2004) On the distribution of the breaking strain of a

343 bundle of brittle elastic fibers. Advances in Applied Probability, 36, 98-115. 
345 Gokhale, S., \& Khare, M. (2005) A hybrid model for predicting carbon monoxide

346 from vehicular exhausts in urban environments. Atmospheric Environment, 39, 4025 -

34740.

349 Johnson, N.L, Kotz, S., \& Balakrishnan, N. (1995) Continuous Univariate

350 Distibutions, Volume 2, $2^{\text {nd }}$ edn. J Wiley.

351

352 Johnson, R.A., Miller, I., \& Freund, J. (2004) Miller and Freund's Probability and

353 Statistics for Engineers, $7^{\text {th }}$ edn. Prentice Hall.

355 Kooijman, S.A.L.M. (1987) Safety Factor for LC//5//0 values allowing for differences

356 in sensitivity among species. Water Research, 21, 269-276.

358 Leroy, D., Giovannoni, J.-M., \& Maystre, L.-Y. (1992) Sampling method to

359 determine a household waste composition variance. Waste Management and

360 Research, 10, 3-12.

362 McBean, E.A., \& Rovers, F.A. (1998) Statistical Procedures for Analysis of

363 Environmental Monitoring Data and Risk Assessment. Prentice-Hall.

365 Palisade Corporation (2007) Best Fit 4.5, http://www.palisade.com.au/bestfit/

366 (January 23, 2008)

368 Sfeir, H., Reinhart, D.R., \& McCauley-Bell, P.R. (1999) An evaluation of municipal 
369 solid waste composition bias sources. Journal of the Air and Waste Management 370 Association, 49, 1096-1102.

371

372 Sharma M., \& E. McBean (2006) A methodology for solid waste characterization

373 based on diminishing marginal returns. Waste Management, 27, 337-344.

374 
377 Table 1. Waste composition data from 22 samples at the Burnaby incinerator, July, 3781998.

380 Table 2. Waste composition data from 20 samples at the Burnaby incinerator, 381 October, 1998.

Table 3. Scored assessment of goodness-of-fit of six distributions (with number of 384 parameters in brackets) to solid waste composition data from Burnaby, Canada. Each 385 entry gives three scores for goodness-of-fit measured by Chi-square, Kolmogorov386 Smirnov, and Anderson-Darling statistics respectively. A score of 3 represents the 387 best fitted distribution, 2 the second-best, 1 third-best, and 0 is assigned for worse 388 than the third-best distribution.

390 Table 4. Goodness-of-fit of five distributions to combinations of solid waste 391 composition data from Burnaby, Canada. Each entry gives three scores for goodness392 of-fit measured by Chi-square, Kolmogorov-Smirnov, and Anderson-Darling statistics 393 respectively. A score of 3 represents the best fitted distribution, 2 the second-best, 1 394 third-best, and 0 is assigned for worse than the third-best distribution.

Table 5. Median Kolmogorov-Smirnov and Anderson-Darling statistics over the twelve waste components for selected two- and three-parameter distributions. 
402 Figure 1. The varied shapes of the log-logistic distribution. (a) a skewed form with

403 mean and standard deviation of $2($ beta $=1.6$; alpha $=2.7)$; (b) a symmetric form with

404 mean of 20 and standard deviation of 2 (beta $=20$; alpha $=18$ ).

405

406 Figure 2. Paper percentage in 22 solid waste samples taken at the Burnaby

407 incinerator, BC, and fit of the data using BestFit to (a) the normal distribution, and (b)

408 the shifted log-logistic distribution.

409

410 Figure 3. Glass percentage in 22 solid waste samples taken at the Burnaby

411 incinerator, BC, and fit of the data using BestFit to the (a) unshifted lognormal

412 distribution, and (b) shifted log-logistic distribution. 

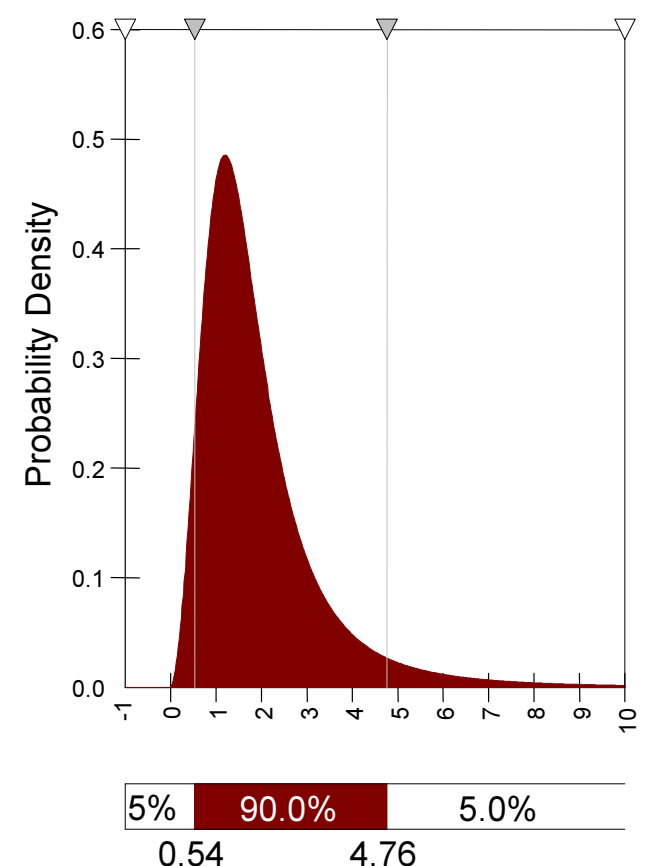
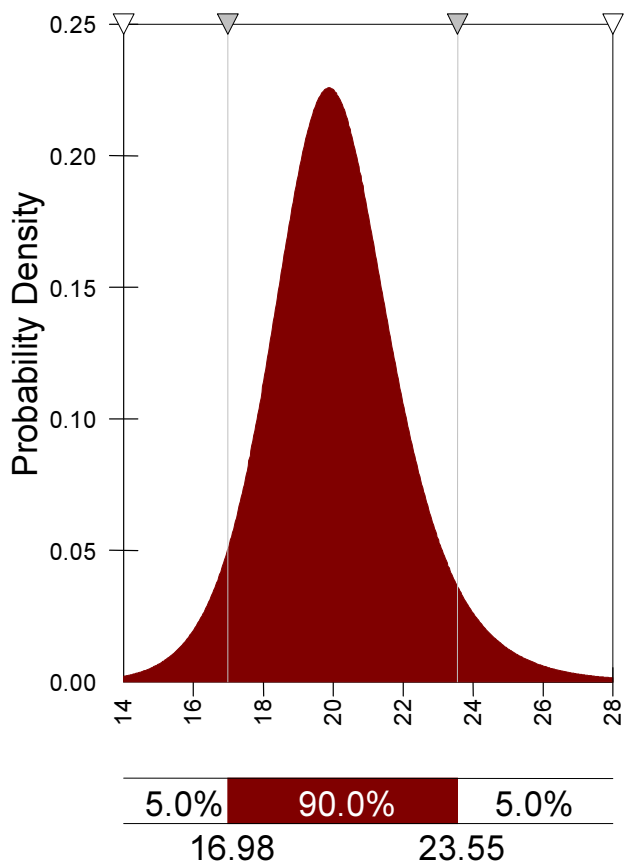

413

415

416

417
Fig. 1: The varied shapes of the log-logistic distribution. (a) a skewed form with mean and standard deviation of $2(\beta=1.6 ; \alpha=2.7)$; (b) a symmetric form with mean of 20 and standard deviation of $2(\beta=20 ; \alpha=18)$. 


\begin{tabular}{|l|l|l|}
\hline Major Waste Component & Mean (\%) & Standard Deviation (\%) \\
\hline Organics & 37.4 & 11.1 \\
\hline Paper & 32.3 & 10.6 \\
\hline Plastics & 13.3 & 5.4 \\
\hline Household Hazardous & 5.9 & 3.0 \\
\hline Metals & 3.4 & 1.5 \\
\hline Glass & 3.1 & 2.3 \\
\hline Inorganic & 2.9 & 3.8 \\
\hline Fines & 1.2 & 1.7 \\
\hline
\end{tabular}

Table 1: Waste composition data from 22 samples at the Burnaby incinerator, July, 1998.

\begin{tabular}{|l|l|l|}
\hline Primary Waste Component & Mean (\%) & Standard Deviation (\%) \\
\hline OCC Paper & 5.22 & 3.48 \\
\hline Film Plastic & 6.70 & 1.72 \\
\hline Plastic (not Film or PVC) & 3.43 & 2.21 \\
\hline Yard and Garden (not grass) & 4.55 & 5.33 \\
\hline
\end{tabular}

Table 2: Waste composition data from 20 samples at the Burnaby incinerator,

\begin{tabular}{|l|l|l|l|l|l|l|l|}
\hline $\begin{array}{l}\text { Waste } \\
\text { Component }\end{array}$ & $\begin{array}{l}\text { Sample } \\
\text { Set }\end{array}$ & $\begin{array}{l}\text { Extreme } \\
\text { Value } \\
{[2]}\end{array}$ & $\begin{array}{l}\text { Inverse } \\
\text { Gauss } \\
{[3]}\end{array}$ & $\begin{array}{l}\text { Logistic } \\
{[2]}\end{array}$ & $\begin{array}{l}\text { Log- } \\
\text { logistic } \\
{[3]}\end{array}$ & $\begin{array}{l}\text { Lognormal } \\
{[3]}\end{array}$ & $\begin{array}{l}\text { Pearson } \\
5[3]\end{array}$ \\
\hline Organics & $\begin{array}{l}\text { July, } \\
98\end{array}$ & $2 / 0 / 0$ & $0 / 1 / 1$ & $0 / 0 / 0$ & $3 / 3 / 3$ & $1 / 0 / 0$ & $0 / 2 / 2$ \\
\hline Paper & $\begin{array}{l}\text { July, } \\
98\end{array}$ & $2 / 0 / 0$ & $0 / 0 / 1$ & $0 / 0 / 0$ & $3 / 3 / 0$ & $0 / 1 / 2$ & $0 / 2 / 3$ \\
\hline Plastics & $\begin{array}{l}\text { July, } \\
98\end{array}$ & $3 / 0 / 2$ & $2 / 2 / 0$ & $1 / 0 / 0$ & $0 / 1 / 1$ & $0 / 0 / 0$ & $0 / 3 / 3$ \\
\hline $\begin{array}{l}\text { Household } \\
\text { Hazardous }\end{array}$ & $\begin{array}{l}\text { July, } \\
98\end{array}$ & $0 / 0 / 0$ & $0 / 0 / 0$ & $2 / 3 / 3$ & $0 / 2 / 2$ & $0 / 1 / 0$ & $0 / 0 / 0$
\end{tabular}




\begin{tabular}{|l|l|l|l|l|l|l|l|}
\hline Metals & $\begin{array}{l}\text { July, } \\
98\end{array}$ & $3 / 2 / 2$ & $0 / 0 / 0$ & $0 / 0 / 0$ & $1 / 3 / 3$ & $0 / 0 / 0$ & $0 / 1 / 0$ \\
\hline Glass & $\begin{array}{l}\text { July, } \\
98\end{array}$ & $3 / 0 / 2$ & $2 / 0 / 1$ & $1 / 0 / 3$ & $0 / 1 / 0$ & $0 / 2 / 0$ & $0 / 3 / 0$ \\
\hline Inorganics & $\begin{array}{l}\text { July, } \\
98\end{array}$ & $3 / 1 / 1$ & $0 / 3 / 2$ & $2 / 0 / 0$ & $0 / 0 / 0$ & $0 / 0 / 0$ & $0 / 0 / 0$ \\
\hline Fines & $\begin{array}{l}\text { July, } \\
98\end{array}$ & $0 / 0 / 0$ & $1 / 2 / 2$ & $0 / 0 / 0$ & $0 / 0 / 0$ & $0 / 0 / 0$ & $2 / 3 / 3$ \\
\hline OCC Paper & $\begin{array}{l}\text { Oct., } \\
98\end{array}$ & $3 / 0 / 0$ & $2 / 0 / 0$ & $0 / 0 / 0$ & $0 / 0 / 2$ & $1 / 1 / 1$ & $0 / 2 / 3$ \\
\hline $\begin{array}{l}\text { Film } \\
\text { Plastic }\end{array}$ & $\begin{array}{l}\text { Oct., } \\
98\end{array}$ & $1 / 0 / 0$ & $0 / 0 / 0$ & $0 / 2 / 2$ & $0 / 3 / 3$ & $0 / 0 / 0$ & $0 / 1 / 1$ \\
\hline $\begin{array}{l}\text { Plastic (not } \\
\text { film or } \\
\text { PVC) }\end{array}$ & $\begin{array}{l}\text { Oct., } \\
98\end{array}$ & $0 / 0 / 0$ & $2 / 3 / 1$ & $0 / 0 / 0$ & $1 / 1 / 3$ & $0 / 2 / 2$ & $0 / 0 / 0$ \\
\hline $\begin{array}{l}\text { Yard and } \\
\text { Garden } \\
\text { (not grass) }\end{array}$ & $\begin{array}{l}\text { Oct., } \\
98\end{array}$ & $2 / 0 / 2$ & $0 / 1 / 0$ & $0 / 0 / 0$ & $0 / 0 / 0$ & $1 / 3 / 1$ & $0 / 0 / 0$ \\
\hline \begin{tabular}{l} 
Total Score \\
\hline
\end{tabular} & 34 & 29 & 19 & 42 & 19 & 34 \\
\hline
\end{tabular}

442

Table 3: Overall weighted assessment of Goodness-of-Fit of six distributions (with number of parameters in brackets) to solid waste composition data from Burnaby, Canada. Each entry gives three scores for goodness-of-fit measured by Chi-squared, Kolmogorov-Smirnov, and Anderson-Darling statistics respectively. A score of 3 represents the best fit distribution, 2 the second-best, 1 third-best, and 0 is assigned for worse than the third-best distribution. 


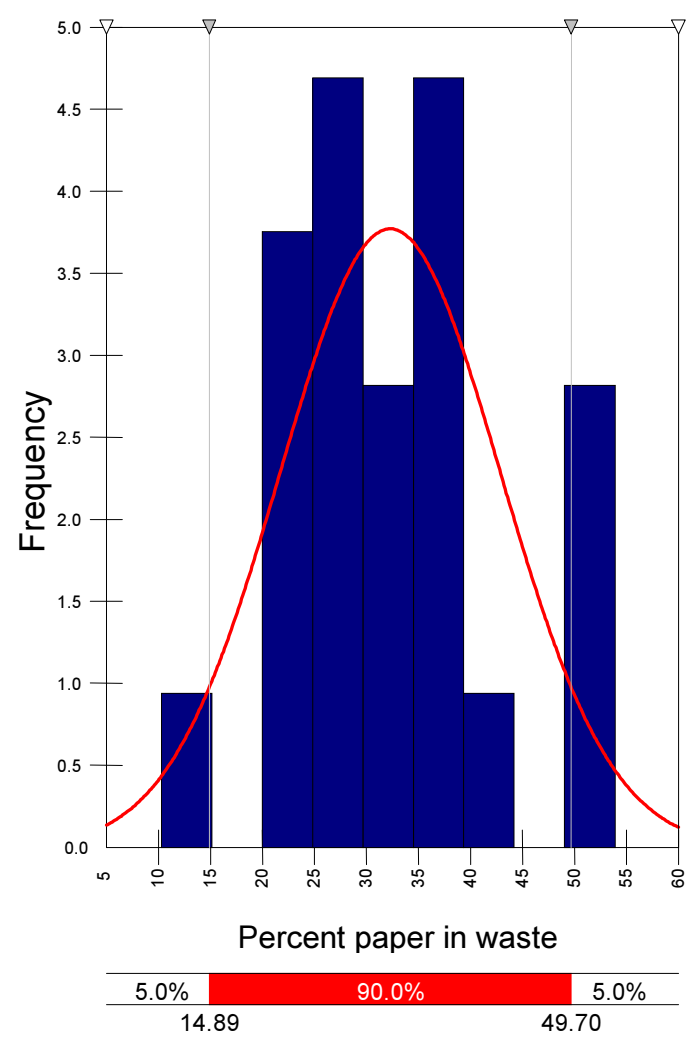

453

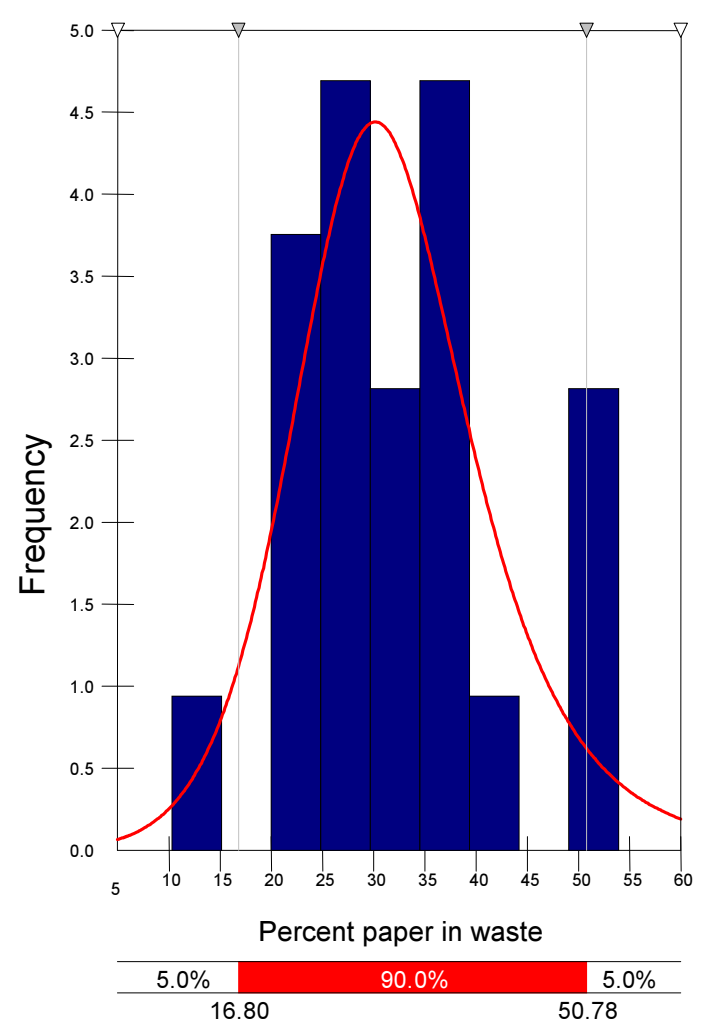

Fig. 2: Paper percentage in 22 solid waste samples taken at the Burnaby incinerator, $\mathrm{BC}$, and fit of the data using BestFit to (a) the normal distribution, and (b) the shifted log-logistic distribution. 


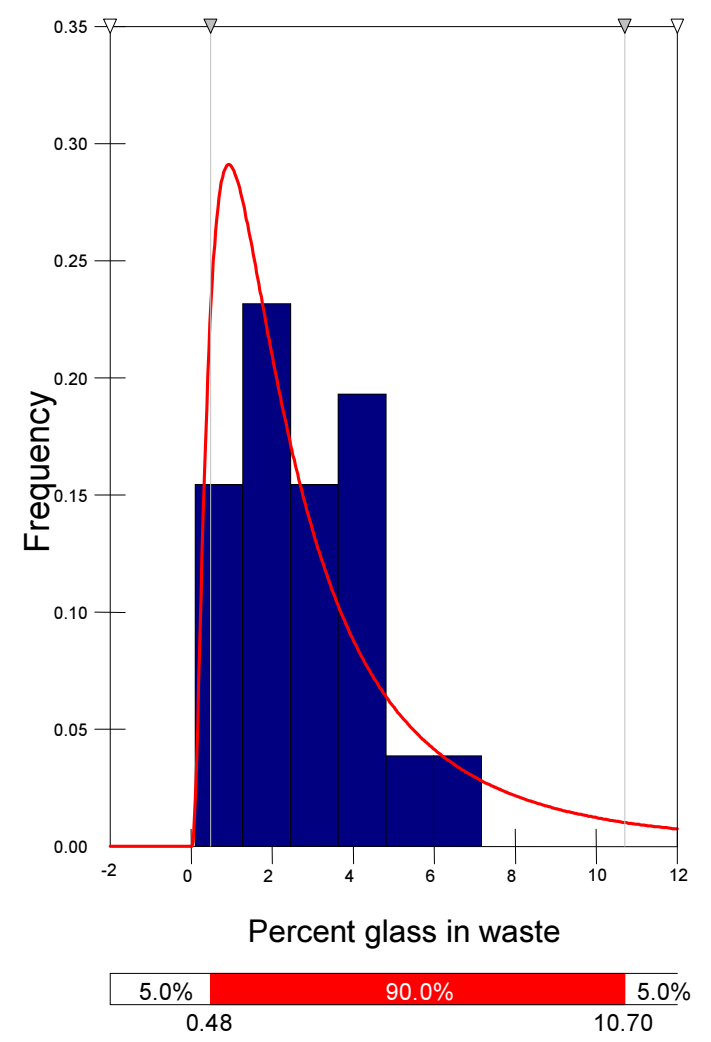

460

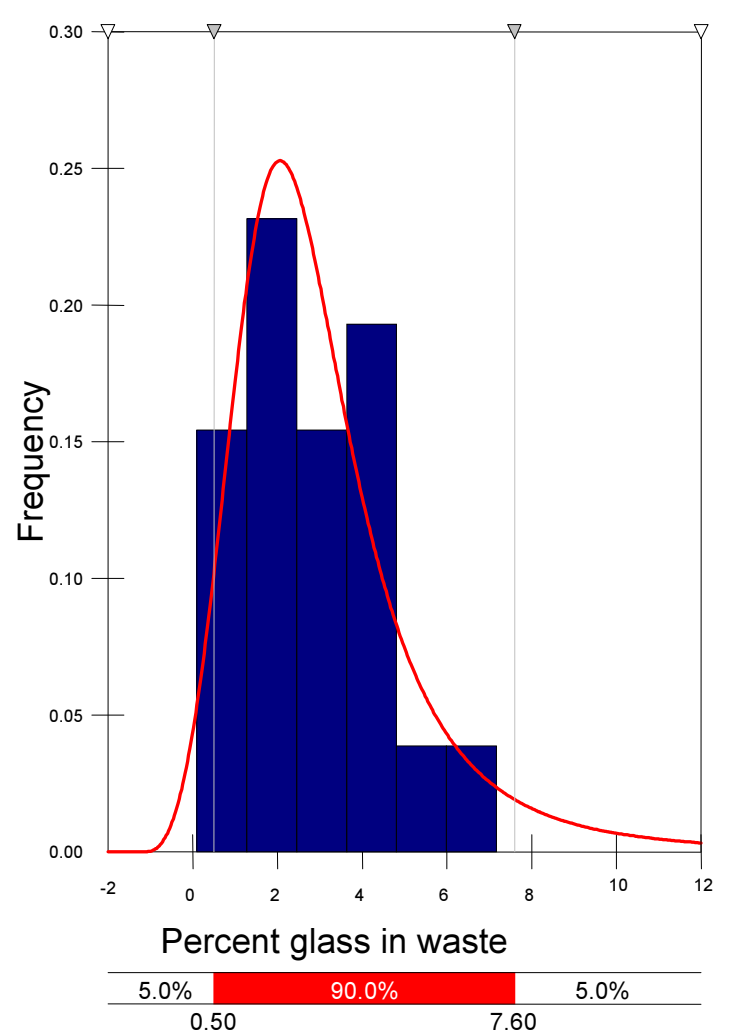

464 Fig. 3: Glass percentage in 22 solid waste samples taken at the Burnaby incinerator, $465 \mathrm{BC}$, and fit of the data using BestFit to the (a) unshifted lognormal distribution, and 466 (b) shifted log-logistic distribution. 


\begin{tabular}{|l|l|l|l|l|l|l|}
\hline $\begin{array}{l}\text { Waste } \\
\text { Combination }\end{array}$ & Mean & $\begin{array}{l}\text { Inverse } \\
\text { Gauss }\end{array}$ & Logistic & $\begin{array}{l}\text { Log- } \\
\text { logistic }\end{array}$ & Normal & $\begin{array}{l}\text { Pearson } \\
5\end{array}$ \\
\hline $\begin{array}{l}\text { Paper }+ \\
\text { Organics }\end{array}$ & 69.7 & $0 / 0 / 0$ & $1 / 3 / 3$ & $0 / 0 / 0$ & $3 / 2 / 2$ & $0 / 0 / 0$ \\
\hline $\begin{array}{l}\text { Paper }+ \\
\text { Plastics }\end{array}$ & 45.6 & $3 / 0 / 1$ & $2 / 2 / 2$ & $1 / 3 / 3$ & $0 / 0 / 0$ & $0 / 0 / 0$ \\
\hline $\begin{array}{l}\text { Metals + Glass } \\
+ \text { Inorganics }\end{array}$ & 9.4 & $1 / 0 / 0$ & $3 / 0 / 0$ & $0 / 3 / 3$ & $0 / 0 / 0$ & $0 / 2 / 2$ \\
\hline Metals + Glass & 6.5 & $3 / 0 / 0$ & $2 / 2 / 2$ & $1 / 3 / 3$ & $0 / 0 / 0$ & $0 / 1 / 1$ \\
\hline
\end{tabular}

468

Table 4: Goodness-of-fit of five distributions to combinations of solid waste composition data from Burnaby, Canada. Each entry gives three scores for goodnessof-fit measured by Chi-squared, Kolmogorov-Smirnov, and Anderson-Darling statistics respectively. A score of 3 represents the best fit distribution, 2 the secondbest, 1 third-best, and 0 is assigned for worse than the third-best distribution.

\begin{tabular}{|l|l|l|l|}
\hline Distribution & No. Parameters & $\begin{array}{l}\text { Median } \\
\text { Kolmogorov- } \\
\text { Smirnov Statistic }\end{array}$ & $\begin{array}{l}\text { Median Anderson- } \\
\text { Darling Statistic }\end{array}$ \\
\hline Log-logistic & 2 & 0.125 & 0.412 \\
\hline Pearson 5 & 2 & 0.184 & 3.34 \\
\hline Log-logistic & 3 & 0.118 & 0.292 \\
\hline
\end{tabular}

Table 5: Median Kolmogorov-Smirnov and Anderson-Darling statistics over the twelve waste components for selected two- and three-parameter distributions. 